\title{
TRUS-guided transperineal prostate $12+X$ core biopsy with template for the diagnosis of prostate cancer
}

\author{
GANG GUO, YONG XU and XU ZHANG \\ Department of Urology, General Hospital of The People's Liberation Army, Beijing 100853, P.R. China
}

Received August 11, 2015; Accepted December 16, 2016

DOI: $10.3892 / \mathrm{ol} .2017 .6051$

\begin{abstract}
The objective of the present study was to explore the clinical value and safety of trans-rectal ultrasound (TRUS)-guided transperineal prostate $12+\mathrm{X}$ core biopsy in the diagnosis of prostate cancer. Patients who received a TRUS-guided transperineal prostate biopsy for suspected prostate cancer at the General Hospital of The People's Liberation Army between September 2009 and May 2014 were retrospectively analyzed, this consisted of 1,300 patients. These patients were randomly divided into the $12+X$ core group or the standard 12-core group. The mean age of all the patients was 70.5 years old. Levels of prostate-specific antigen, digital rectal examination, transrectal ultrasound and magnetic resonance imaging (MRI) were checked and used as reference prior and subsequent to the biopsy procedure. The $12+\mathrm{X}$ core group consisted of 937 patients and the 12-core group consisted of 363 patients. The mean number of core samples taken from both groups was 14.5 (ranging from 12 to 24) and the mean operative time of the whole group was 20.4 min (ranging from 15 to $40 \mathrm{~min}$ ). The puncture positive detection rate of abnormal rectal examination, trans-rectal ultrasound, and MRI was 24.0, 30.1, and 59.2\%, respectively, whereas the puncture positive rate was $47.2 \%$ in $12+X$ core group and $34.5 \%$ in 12-core group. Improved prostate needle biopsy with $12+\mathrm{X}$ cores was found to have significantly higher detection rate than that with 12 cores as well as fewer post-operative complications, therefore making the method ideal for diagnosing prostate cancer.
\end{abstract}

\section{Introduction}

With an increase in life expectancy and changes in dietary structure, the incidence rate of prostate cancer has shown an upward trend been in China, at 4.3 per 100,000 according to a

Correspondence to: Dr Xu Zhang, Department of Urology, General Hospital of The People's Liberation Army, 28 Fuxing Road, Haidian, Beijing 100853, P.R. China

E-mail: xu_zhang0209@163.com

Key words: prostate cancer, prostate needle biopsy, $12+\mathrm{X}$ cores, prostate-specific antigen, transperineal study published in 2008 (1). Although prostate specific antigen (PSA) tests, digital rectal examination (DRE), transrectal ultrasound (TRUS) and magnetic resonance imaging (MRI) have been widely adopted in the diagnosis of numerous prostate diseases, biopsy is the only current diagnostic technique for prostate cancer (2). Prostate biopsy may be performed transrectally, the most common approach (3), or through the urethra or perineum. In addition, the level of PSA in blood is often used to identify prostate cancer, but it is not a definitive indicator as PSA level can also be affected by other factors such as inflammation and infection. At present, prostate biopsy is required for the specific diagnosis of prostate cancer.

However, the number of core samples that should be taken during prostate biopsy is still debated. It is generally accepted that increasing the number of samples taken could improve the detection rate of prostate cancer (4-7), but the risk of side-effects increase too. In a retrospective study of 3,000 patients, the number of clinical complications increased significantly with the increase of number of samples taken during transperineal prostate biopsy (6). However, if fewer samples are taken this could lead to the cancerous lesions being missed, under-sampling and an increased false negative rate $(4,5)$. As a result, some patients would have to undergo prostate biopsy again.

Previously, imaging techniques-based biopsy has provided a targeted and advanced modality for prostate cancer detection (3). Even though an increasing the number of random samples taken may have only marginal diagnostic value, increasing the number of targeted core samples (transperineal template-guided biopsies) taken, which are only taken from lesions identified and suspected via preoperative imaging tests to be cancerous, may be a better approach for transperineal prostate biopsy. The present study aimed to investigate whether this $12+\mathrm{X}$ modality, as described in the Methods, for prostate biopsy could be an improvement compared with the traditional 12-core modality by comparing the detection rate and number of postoperative complications of the two methods.

\section{Materials and methods}

Clinical samples. The data of patients who received TRUS-guided prostate biopsy for suspected prostate cancer in the General Hospital of The People's Liberation Army (Beijing, China) between September 2009 and May 2014 was retrospectively analyzed. The present stidu was approved by 
the ethics committee of the General Hospital of The People's Liberation Army. In total, 1,300 patients were taken up in the study, with a mean age of 70.5 (34-98) years. Among these patients, 785 patients were suspected to have prostate cancer subsequent to the detection of an elevated level of PSA. In total, 392 patients were suspected to have prostate cancer due to abnormalities in the prostate detected via ultrasound or MRI; 912 of the cases were accompanied with obstructive symptoms of the lower urinary tract such as frequent urination, urgent urination, nocturia and dysuria. PSA levels were monitored twice and a DRE, transrectal ultrasound and enhanced dynamic MRI were performed on each patient. The inclusion criteria consisted of patients with: Total (T)-PSA $>10 \mathrm{ng} / \mathrm{ml}$, regardless of free/total (f/t) PSA or PSA density (PSAD); T-PSA between 4 and $10 \mathrm{ng} / \mathrm{ml}$, with a concomitant abnormal f/t PSA or PSAD measurement; a palpable and hard nodule through DRE; and hypoechoic regions of the prostate identified through TRUS or transabdominal ultrasound (TAUS). The exclusionary criteria were: A history of prostate cancer; undergoing anti-androgen therapies; and other variables including patients with a local skin infection, blood coagulation dysfunction, diabetes mellitus and/or not well-controlled blood glucose, or cachexia.

Among the included patients, 1,043 were receiving their first biopsy. Patients were randomly assigned to the 12-core group or the $12+X$ core group (Table I). For the patients of the $12+X$ core group, additional core samples were taken from suspected cancerous lesions identified through pre-biopsy MRI and ultrasound examinations. The Gleason scores of the diagnosed patients were tested (8). All patients provided informed consent prior to the beginning of the study.

Surgery. The coagulation function of patients including prothrombin time, activated partial thromboplastin time, thrombin time and fibrinogen was tested by peripheral blood. Routine blood and urine tests were also performed prior to the biopsy. Cifran (0.5 g, 4 times a day) and metronidazole ( $0.5 \mathrm{~g}$, twice a day) were administered orally 1 day prior to biopsy to prevent infection. On the day of biopsy, glycerin was administered rectally to facilitate defecation. Signa Excite HD 3.0T MRI machine (GE Healthcare Bio-Sciences, Pittsburgh, PA, USA) and a B-K 2102 Ultrasound (BK Medical ApS, Herlev, Denmark) were used prior to the operation to obtain images with suspected lesions marked (Figs. 1-2). The local anesthetic lidocaine (1\%) was administered to 973 patients via injection through the perineal subcutaneous tissue and outside the prostatic capsule. Caudal block anesthesia was administered to 75 patients via lidocaine (1\%) injection. The remaining 252 patients received epidural anesthesia, a mixture of $0.375 \%$ ropivacaine $+1 \%$ lidocaine $0.6 \mathrm{ml} / \mathrm{kg}$.

The patients were then placed in the lithotomy position. Following a routine perineal disinfection procedure, a rectal ultrasound probe (Dual-plane; Computerised Medical System Company, Inc., St. Louis, MO, USA) was placed in the rectum of the patients to observe the shape of their prostates. Subsequent to the fixation of the probe and the perineal template (Centers for Medicare and Medicaid Services, Baltimore, MD USA), the ultrasound-guided and perineal template-mapped prostate biopsy was conducted on the patients. For the patients of the 12-core group, the locations of 12-core samples taken are showed in Fig. 3. For the patients of the 12+X core group, additional core samples were taken from suspected cancerous lesions identified through pre-biopsy MRI and ultrasound examinations (Fig. 3).

Oral administration of the aforementioned dose and concentration of cifran and metronidazole was continued 3 days post-operatively. A high water intake was recommended for patients presenting with secondary hematuria. If the symptoms did not resolve themselves, patients were catheterized until full remission. Patients that presented with urinary retention were catheterized for 1 week and orally administered with tamsulosin hydrochloride in the form of sustained release capsules ( $0.2 \mathrm{mg}, 4$ times a day). All patients were followed up 1 month subsequent to the operation to record their pathological results and any complications.

Statistical analysis. Statistical analysis was conducted to compare the differences in PSA, f/t PSA and PSAD between the 2 groups and the positive rate of different auxiliary examination methods. SPSS 13.0 (SPSS, Inc., Chicago, IL, USA) was used to perform the data analysis. A $\chi^{2}$ test was conducted to compare the positive detection rates of 2 groups. $\mathrm{P}<0.05$ was considered to indicate a statistically significant difference.

\section{Results}

Biopsies were successfully performed on all patients. The mean number of samples taken from patients in the $12+\mathrm{X}$ core group was 15.5 , ranging from 13 to 24 core samples per patient. The operation time ranged between 15 and $30 \mathrm{~min}$, with a mean of 20.4 min. Based on the biopsy test results, the presence of prostate cancer was confirmed for 540 patients (41.5\%). Among this group, 527 patients were found to exhibit adenocarcinoma and 13 patients were affected by other types of cancer. In addition, it was confirmed that 57 patients displayed prostate intraepithelial neoplasia (4.4\%) and that 703 patients exhibited prostate hyperplasia and prostatitis $(54.1 \%)$. The Gleason scores of the diagnosed patients are shown in Table II. Compared with the 12-core group, $8.7 \%$ patients appeared to show an increase in Gleason scores in the $12+\mathrm{X}$ core group.

The positive detection rate of the 12-core group was $34.4 \%$ (125/363), while that of the $12+X$ core group was $44.3 \%$ (415/937). The positive detection rates for the patients are expressed in Table III. Patients with abnormalities identified through DRE, TRUS, or MRI were found to have positive rates of $\sim 24.0,30.1$, and $59.2 \%$, respectively. The overall incidence rate of complications was $19.0 \%$ (247/1,300), including 6 patients with lidocaine absorption into the blood, 201 patients with post-operative hematuria, 14 patients with perineal hematoma, 21 patients with acute urinary retention and 5 patients with urinary tract infections accompanied by fever. The aforementioned complications were all resolved subsequent to treatment and did not result in any severe complications. The incidence rate of post-operative complications for the 12 core and $12+\mathrm{X}$ core groups were $16.8 \%$ (61/363) and $19.9 \%$ (186/937), respectively. The difference between the groups was demonstrated to be insignificant $(\mathrm{P}=0.175)$. A comparison of a positive needles outcome of prostate cancer in the different groups and the distribution of the lesions are displayed in Table IV. 
Table I. Patient information.

\begin{tabular}{lcc}
\hline Characteristic & $\begin{array}{c}\text { 12-core } \\
\text { group }\end{array}$ & $\begin{array}{c}12+\mathrm{X} \text { core } \\
\text { group }\end{array}$ \\
\hline Number of cases & 363 & 937 \\
Mean age (years) & 71.1 & 70.2 \\
Ethnicity-Han, \% & 95.0 & 96.1 \\
Family history of prostate cancer, \% & 3.6 & 3.9 \\
Mean prostate volume, ml & 39.2 & 37.8 \\
Mean peak value of TPSA, ng/ml & 15.4 & 16.7 \\
Anomaly in DRE, \% & 66.9 & 65.1 \\
Anomaly in TRUS, \% & 72.1 & 74.2 \\
Anomaly in MRI, \% & 70.5 & 72.4 \\
First biopsy, \% & 77.4 & 81.3 \\
Mean surgery time, min & 17.7 & 21.5 \\
Mean number of core samples taken & 12 & 15.5 \\
\hline
\end{tabular}

DRE, digital rectal examination; MRI, magnetic resonance imaging; TPSA, total prostate specific antigen; TRUS, transrectal ultrasound.

Table II. Gleason score of the two groups.

\begin{tabular}{lccc}
\hline $\begin{array}{l}\text { Gleason } \\
\text { Score }\end{array}$ & $\begin{array}{c}12 \text { core } \\
\text { group, } \%\end{array}$ & $\begin{array}{c}12+\mathrm{X} \text { core } \\
\text { group, } \%\end{array}$ & P-value \\
\hline Patients, n & 125 & 415 & \\
$\leq 6$ & 35.2 & 26.6 & 0.063 \\
7 & 34.4 & 40.0 & 0.127 \\
8 & 15.2 & 18.3 & 0.341 \\
9 & 13.6 & 13.7 & 0.934 \\
10 & 1.2 & 1.4 & 0.874 \\
\hline
\end{tabular}

\section{Discussion}

With the wide application of TRUS in clinical practice, TRUS-guided prostate biopsy has become the gold standard for diagnosis of prostate cancer (9). Hodge introduced the TRUS-guided 6 core biopsy in 1989 (7). This technique was later criticized for its high false negative rate, which was as high as $20-30 \%$ (10). Therefore, 8-, 10-, 12- and 13-core and saturated puncture techniques were proposed to improve the detection rate for prostate cancer. Numerous studies have confirmed the diagnostic value of an increase in the number of samples taken for the detection of prostate cancer $(6,7,11,12)$. However, alternative studies found that a slight increase in the number of cores would not significantly increase the detection rate of prostate cancer $(13,14)$. A possible explanation for such a dispute might be associated with the fact that initial biopsies mostly took samples randomly. The present study found that taking additional samples from prostate sites suspected to be cancerous, identified using pre-operative imaging tests, provided an improved biopsy modality. The $12+\mathrm{X}$ core biopsy modality, which combined random puncture with targeted puncture, enhanced detection rate by $28.8 \%$ with an average of only 3.5 additional samples taken.

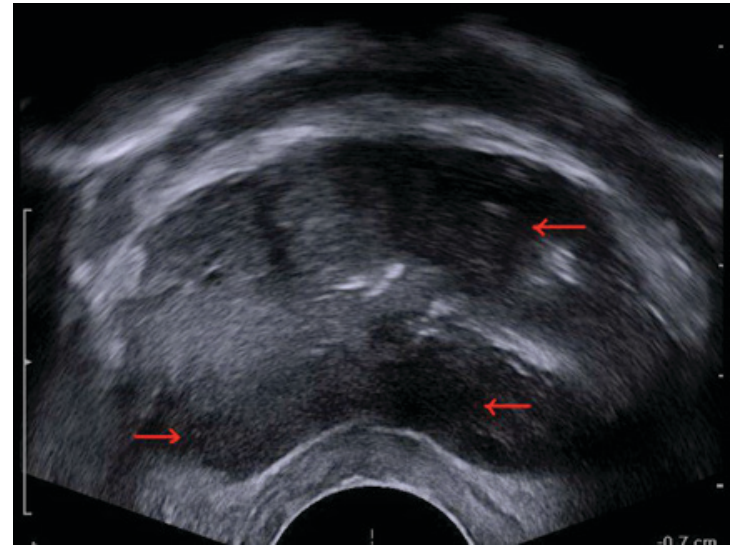

Figure 1. Hypointensive lesions identified on both sides of the peripheral zone and left transitional zone of the prostrate through trans-rectal ultrasound.

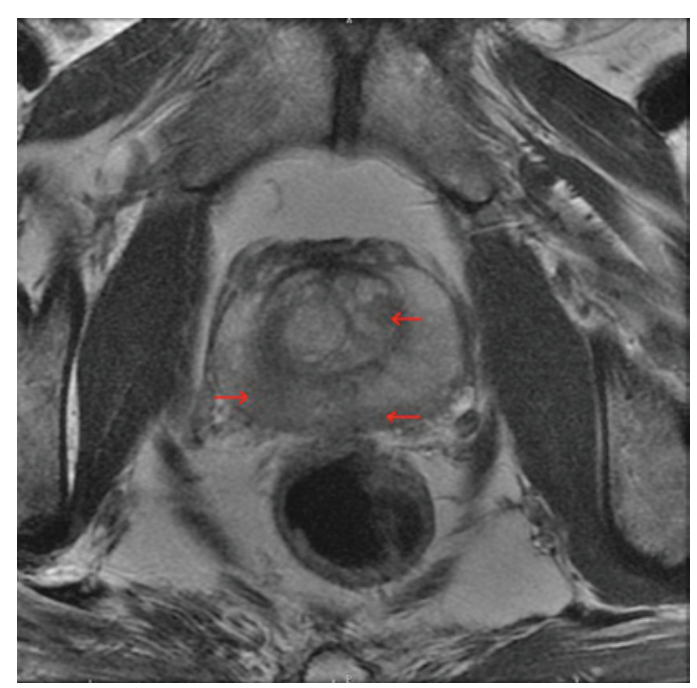

Figure 2. Hypointensive lesions of the prostrate identified through T2-weighted magnetic resonance imaging.

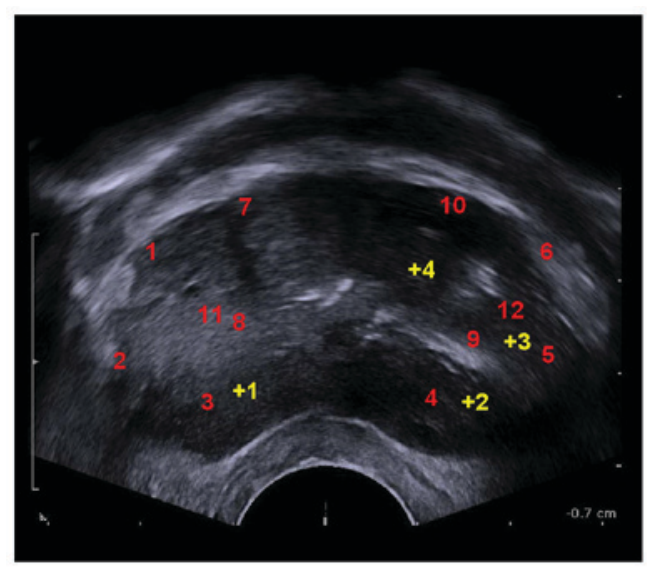

Figure 3. Locations of standard 12-core and $12+\mathrm{X}$ core prostate biopsies as identified by rectal ultrasound. The numbers were manually added in image editing software. Red, 12 core; yellow, $12+$.

Chen et al (13) found that $\sim 80 \%$ patients with prostate cancer exhibited multifocal distribution, mostly located in the peripheral zone of the prostate. Small-sized cancerous lesions 
Table III. Positive rates for patients with different PSA, f/t PSA and PSAD.

\begin{tabular}{|c|c|c|c|c|c|}
\hline \multirow[b]{2}{*}{ Group } & \multicolumn{2}{|c|}{12 core group } & \multicolumn{2}{|c|}{$12+X$ cores group } & \multirow[b]{2}{*}{ P-value } \\
\hline & Patients & Positive rate, $\%$ & Patients & Positive rate, $\%$ & \\
\hline \multicolumn{6}{|c|}{ TPSA, ng/ml } \\
\hline$<4$ & 22 & 9.1 & 55 & 21.8 & 0.003 \\
\hline $4-10$ & 77 & 9.1 & 216 & 21.3 & 0.004 \\
\hline $10-20$ & 148 & 16.1 & 373 & 39.7 & 0.015 \\
\hline$>20$ & 116 & 61.2 & 293 & 80.5 & 0.041 \\
\hline \multicolumn{6}{|l|}{$\mathrm{f} / \mathrm{tPSA}$} \\
\hline$\geq 0.16$ & 21 & 9.5 & 56 & 25.0 & $<0.001$ \\
\hline$<0.16$ & 56 & 8.9 & 160 & 20.0 & 0.021 \\
\hline \multicolumn{6}{|l|}{ PSAD } \\
\hline$\geq 0.15$ & 276 & 15.2 & 734 & 23.4 & 0.037 \\
\hline$<0.15$ & 87 & 7.5 & 203 & 10.1 & 0.234 \\
\hline Total & 363 & 34.4 & 937 & 44.3 & 0.039 \\
\hline
\end{tabular}

f/tPSA, ratio of free prostate specific antigen with total prostate specific antigen; PSAD, prostate specific antigen density; TPSA, total prostate specific antigen.

Table IV. Comparison of a positive needles outcome of prostate cancer and the distribution of the lesions.

\begin{tabular}{lccc}
\hline Distribution & $\begin{array}{c}\text { 12 core } \\
\text { group, \% }\end{array}$ & $\begin{array}{c}\text { 12+X core } \\
\text { group, \% }\end{array}$ & P-value \\
\hline Positive needle, $\mathrm{n}$ & 4.3 & 5.1 & 0.254 \\
Front $^{\mathrm{a}}$ & 84.1 & 85.3 & 0.763 \\
Back $^{\mathrm{a}}$ & 80.4 & 84.2 & 0.127
\end{tabular}

${ }^{a}$ Using Fig. 3 as an example, the locations of 1, 7, 9, 6, 11 and 12 were front and 2, 3, 4, 5, 8 and 10 were back.

were mainly located in the apex zone. For prostate cancer patients with normal or slightly elevated PSA, most lesions were located in the apex zone (14). Vis et al (15) conducted an in vitro simulation experiment on the specimens taken from 40 patients that underwent radical prostatectomy and found that the positive rate was higher in transperineal prostate biopsies compared with transrectal prostate biopsies. The comparatively lower false negative rate of perineal prostate biopsy may be explained by the fact that during a perineal prostate biopsy the needle will penetrate the apex region of the prostate. More tissue can be obtained from the peripheral zone of the prostate, which is also the predilection site of prostate cancer (16). However, with respect to transrectal prostate biopsies, more tissue will be obtained from the transitional zone of the prostate, and the peripheral zone of the prostate is more likely to be missed. However, there are also studies suggesting that there is no significant difference between these two approaches in terms of the false negative rate (17-19). As a result, a widely accepted perspective is that the number of puncture cores is more important than the biopsy approach taken (20).
Perineal prostate biopsy was chosen in the present study because this approach allows the use of perineal templates. The use of perineal templates in perineal prostate biopsies can overcome the deviation away from the site of interest caused by using a long needle, and the needle parallel to the probe can avoid injuring the rectum. Additionally, an even distribution of needle gage between 0.5 and $1 \mathrm{~cm}$ may effectively reduce false negative rate, theoretically (21). The present study suggests other benefits of transperineal prostate biopsy. Firstly, disinfecting perineal skin is much easier than disinfecting that of the rectum. As a result, the rate of biopsy-associated infection can be greatly reduced, and the risk of post-operative severe infection can be effectively controlled via the administration of prophylactic antibiotics taken one day prior to the operation (22). Secondly, due to the reduced rate of complications associated with transperineal prostate biopsy, increasing the number of samples taken would be more advisable compared with alternative prostate biopsies. In the present study, more samples were taken in $12+\mathrm{X}$ core group compared with the 12-core group, but the incidence rate of complications did not increase significantly between groups.

Previous studies highlight the clinical significance of DRE, TRUS, MRI and PSA as indicators in the diagnosis of prostate cancer $(23,24)$. The present study suggests that high-field MRI could greatly enhance the detection rate of prostate cancer. The close analysis of images obtained from an MRI of the prostate helped identify suspected cancerous lesions, and TRUS-guided prostate biopsies targeting these lesions significantly enhanced the detection rate of prostate cancer. PSA is still a clinically important index for diagnosing prostate cancer. The positive detection rate is significantly higher for patients with T-PSA $\geq 10 \mathrm{ng} / \mathrm{ml}$, T-PSA between 4 and $10 \mathrm{ng} / \mathrm{ml}, \mathrm{F} / \mathrm{T}$ PSA $<0.16$ and PSAD $\geq 0.15$. Therefore, the aforementioned indicators should be fully analyzed prior to the selection and implementation of biopsy, especially for 
patients with hyperplasia of the prostate gland and PSA values in the gray area. In previous years, with the rapid development of auxiliary imaging techniques, new high-accuracy biopsy techniques have emerged, including MRI-guided prostate biopsy, transrectal TRUS and MRI image fusion-guided prostate biopsy, real-time ultrasound elastography-guided prostate biopsy and ultrasound histoscanning, which can significantly enhance the detection rate of prostate cancer (25-27).

The present study demonstrates that images obtained from enhanced MRI facilitate the analysis and identification of cancer lesions. The TRUS-guided transperineal prostate $12+\mathrm{X}$ core biopsy with template can significantly enhance the detection rate of prostate cancer, due to the combination of random puncture with targeted puncture. In addition, this biopsy modality exhibits good accuracy and safety. Therefore, the technique presented in the present study is advisable for clinical practice.

\section{Acknowledgements}

The present study was supported by the Clinical research support fund of the General Hospital of The People's Liberation Army (grant no. 2015FC-TSYS-2008). The authors thank Professor Zhang for technical support and assistance during the surgical procedure.

\section{References}

1. Peng P, Gong YM, Bao PP, Ke JZ, Xiang YM, Zhang ML and Zheng Y: Estimates and prediction of prostate cancer incidence, mortality and prevalence in China, 2008. Zhonghua Liu Xing Bing Xue Za Zhi 33: 1056-1059, 2012 (In Chinese).

2. Carter HB: American Urological Association (AUA) guideline on prostate cancer detection: Process and rationale. BJU Int 112: 543-547, 2013

3. Simmons LA, Ahmed HU, Moore CM, Punwani S, Freeman A, Hu Y, Barratt D, Charman SC, Van der Meulen J and Emberton M The PICTURE study-prostate imaging (multi-parametric MRI and Prostate HistoScanning ${ }^{\mathrm{TM}}$ ) compared to transperineal ultrasound guided biopsy for significant prostate cancer risk evaluation. Contemp Clin Trials 37: 69-83, 2014.

4. Abd TT, Goodman M, Hall J, Ritenour CW, Petros JA, Marshall FF and Issa MM: Comparison of 12-core versus 8-core prostate biopsy: Multivariate analysis of large series of US veterans. Urology 77: 541-547, 2011.

5. Yoon BI, Shin TS, Cho HJ, Hong SH, Lee JY, Hwang TK and Kim SW: Is it effective to perform two more prostate biopsies according to prostate-specific antigen level and prostate volume in detecting prostate cancer? Prospective study of 10-core and 12-core prostate biopsy. Urol J 9: 491-497, 2012.

6. Pepe $\mathrm{P}$ and Aragona F: Morbidity after transperineal prostate biopsy in 3000 patients undergoing 12 vs 18 vs more than 24 needle cores. Urology 81: 1142-1146, 2013.

7. Hodge KK, McNeal JE, Terris MK and Stamey TA: Random systematic versus directed ultrasound guided transrectal core biopsies of the prostate. J Urol 142: 71-75, 1989.

8. Zakian KL, Sircar K, Hricak H, Chen HN, Shukla-Dave A, Eberhardt S, Muruganandham M, Ebora L, Kattan MW, Reuter VE, et al: Correlation of proton MR spectroscopic imaging with gleason score based on step-section pathologic analysis after radical prostatectomy. Radiology 234: 804-814, 2005.

9. Eskicorapci SY, Baydar DE, Akbal C, Sofikerim M, Günay M, Ekici S and Ozen H: An extended 10-core transrectal ultrasonography guided prostate biopsy protocol improves the detection of prostate cancer. Eur Urol 45: 444-449, 2004.
10. De Sutter Ph, Coibion M, Vosse M, Hertens D, Huet F, Wesling F, Wayembergh M, Bourdon C and Autier Ph: A multicentre study comparing cervicography and cytology in the detection of cervical intraepithelial neoplasia. Br J Obstet Gynaecol 105: 613-620, 1998.

11. Bjurlin MA and Taneja SS: Standards for prostate biopsy. Curr Opin Urol 24: 155-161, 2014.

12. Rochester MA, Griffin S, Chappell B and McLoughlin J: A prospective randomised trial of extended core prostate biopsy protocols utilizing 12 versus 15 cores. Urol Int 83: 155-159, 2009.

13. Chen ME, Johnston DA, Tang K, Babaian RJ and Troncoso P: Detailed mapping of prostate carcinoma foci: Biopsy strategy implications. Cancer 89: 1800-1809, 2000.

14. Yan W, Li H, Zhou Y, Huang Z, Rong S, Xia M, Ji Z, Chen J and Jiang Y: Prostate carcinoma spatial distribution patterns in Chinese men investigated with systematic transperineal ultrasound guided 11-region biopsy. Urol Oncol 27: 520-524, 2009.

15. Vis AN, Boerma MO, Ciatto S, Hoedemaeker RF, Schröder FH and van der Kwast TH: Detection of prostate cancer: A comparative study of the diagnostic efficacy of sextant transrectal versus sextant transperineal biopsy. Urology 56: 617-621, 2000.

16. Engelbrecht MR, Huisman HJ, Laheij RJ, Jager GJ, van Leenders GJ, Hulsbergen-Van De Kaa CA, de la Rosette JJ, Blickman JG and Barentsz JO: Discrimination of prostate cancer from normal peripheral zone and central gland tissue by using dynamic contrast-enhanced MR imaging. Radiology 229: 248-254, 2003

17. Udeh EI, Amu OC, Nnabugwu II and Ozoemena O: Transperineal versus transrectal prostate biopsy: Our findings in a tertiary health institution. Niger J Clin Pract 18: 110-114, 2015.

18. Chang DT, Challacombe B and Lawrentschuk N: Transperineal biopsy of the prostate-is this the future? Nat Rev Urol 10: 690-702, 2013.

19. Bittner N, Merrick GS, Butler WM, Bennett A and Galbreath RW: Incidence and pathological features of prostate cancer detected on transperineal template guided mapping biopsy after negative transrectal ultrasound guided biopsy. J Urol 190: 509-514, 2013.

20. Wagenlehner FM, Pilatz A, Waliszewski P, Weidner W and Johansen TE: Reducing infection rates after prostate biopsy. Nat Rev Urol 11: 80-86, 2014.

21. Moore CM, Robertson NL, Arsanious N, Middleton T, Villers A, Klotz L, Taneja SS and Emberton M: Image-guided prostate biopsy using magnetic resonance imaging-derived targets: A systematic review. Eur Urol 63: 125-140, 2013.

22. Fiard G, Hohn N, Descotes JL, Rambeaud JJ, Troccaz J and Long JA: Targeted MRI-guided prostate biopsies for the detection of prostate cancer: Initial clinical experience with real-time 3 -dimensional transrectal ultrasound guidance and magnetic resonance/transrectal ultrasound image fusion. Urology 81: 1372-1378, 2013.

23. Villers A: Words of wisdom. Re: Improving detection of clinically significant prostate cancer: MRI/TRUS fusion-guided prostate biopsy. Eur Urol 65: 1218-1219, 2014.

24. Panebianco V, Sciarra A, Marcantonio A, Forte V, Biondi T, Laghi A and Catalano C: Conventional imaging and multiparametric magnetic resonance (MRI, MRS, DWI, MRP) in the diagnosis of prostate cancer. Q J Nucl Med Mol Imaging 56: 331-342, 2012.

25. Correas JM, Tissier AM, Khairoune A, Khoury G, Eiss D and Hélénon O: Ultrasound elastography of the prostate: State of the art. Diagn Interv Imaging 94: 551-560, 2013.

26. Schiffmann J, Fischer J, Tennstedt P, Beyer B, Böhm K, Michl U, Graefen M and Salomon G: Comparison of prostate cancer volume measured by HistoScanning ${ }^{\mathrm{Tm}}$ and final histopathological results. World J Urol 32: 939-944, 2014.

27. Clyne M: Prostate cancer: Visual estimation versus software fusion for MRI-targeted biopsy. Nat Rev Urol 11: 5, 2014. 